\title{
Just doing it: Theorising Integrated Marketing Communications (IMC) practices
}

\begin{tabular}{|r|l|}
\hline Journal: & European Journal of Marketing \\
\hline Manuscript ID & EJM-08-2015-0595.R1 \\
\hline Manuscript Type: & Original Article \\
\hline Keywords: & $\begin{array}{l}\text { Integrated marketing communications, Practice, Practice Theory, } \\
\text { Organizational behaviour, Marketing planning, Retail marketing }\end{array}$ \\
\hline \multicolumn{2}{|l}{} \\
\hline
\end{tabular}




\section{Abstract Purpose}

While Integrated Marketing Communication (IMC) is a well-known concept in academia, there is insufficient theorisation on what it means 'to do' IMC in practice. Despite broad acceptance for IMC, there has been scant application of available organisational and sociological theories to illuminate actual IMC practices in the field. Drawing from the Practice Turn' in management studies, this paper elaborates on the concept of 'TMC practice' and provides an empirical exposition of how integration is enacted in the lifeworlds of marketing practitioners.

\section{Design/Methodology/Approach}

The paper introduces Practice Theory as a lens through which to study IMC practices. Using qualitative coding and interpretative analysis, the framework was operationalised in the context of a two-year organisational ethnography encompassing IMC planning and implementation activities at a leading Swedish retailer.

\section{Findings}

Findings demonstrate how practitioners develop explicit and implicit strategies to enact strategic integration. The study conceptualises IMC as set of interrelated practices, or routinised behaviours, which are repeated and organised by social/formal rules and conventions. In the ethnographic context of the study, 'TMC as practice' is exbibited in the forms of (1) routines, (2) material set-ups, (3) rules and procedures, (4) cultural templates, and (5) teleoaffective structures.

\section{Originality/value}

The paper proposes a novel set of theoretical and methodological tools that can be used to understand how IMC lives as a set of practices inside organisations. It specifically conceptualises the link between mental and objectified, materialised and routinised activities that has previously been escaping the sphere of theorisation. By creating language and tools to capture bitherto unmodellable phenomena, the paper opens many new avenues for future research. 


\section{Introduction}

The novelty of offering 'integration' has made Integrated Marketing Communication (IMC) a standard component in advertising agencies' offerings over the past three decades (Kitchen et al., 2008; Kliatchko and Schultz, 2015). Recent years' shift of marketing budgets from traditional advertising to below-the-line promotion and to the complex and fragmented world of digital media, has made IMC's promises of strategic synergy more relevant and valuable to clients than ever (Kitchen and Burgmann, 2010; Moriarty and Schultz, 2012).

Over time, the conceptual advancement of IMC has been continuously debated (for overviews, see Kitchen et al., 2004a; Kliatchko, 2008; Muñoz-Leiva et al., 2015) and a universally agreed upon definition is still lacking (see, for example, Kerr et al., 2008; Moriarty and Schultz, 2012; Schultz et al., 2014).

Despite definitional disagreements, IMC theorists tend to rest their arguments on the normative proposition that 'integration of marketing communications is good', and academic IMC-proponents have over the years been prescribing solutions to achieve more and better strategic integration. However, there are arguments in the field that in order to advance IMC conceptually, we also need to gain better understanding of how IMC works in actual business 'practice' - in other words, in terms of what practitioners actually do with it (Kitchen et al., 2004b).

With increasing intensity, researchers have observed that there are discrepancies between what IMC theories prescribe and what practitioners actually do (Kitchen et al., 2004b). It has also been observed that not only does the implementation of IMC in real life diverge from the notion of 'ideal' IMC (Kitchen et al., 2004b), it also appears that interpretations, variations and operationalisations of IMC are contextual and dependent on diverse factors such as organisational variables, broader culture and the professional background of individual practitioners (Beard, 1997; Eagle and Kitchen, 2000; Ots and Nyilasy, 2015). Some have even suggested that the evolution of coordinating practices performed by reallife marketing organisations and business units may in fact be quite independent of the progression of theoretical conceptualisations of IMC (Cornelissen, 2001; Cornelissen and Lock, 2000; Hutton, 1996). In other words, there are no signs of convergence between IMC prescriptions and practice. It has been argued that in order to bring theory forward, academics need to embrace this heterogeneity and complexity and better understand the integrating activities that firms and practitioners conduct in their own lifeworlds (Beverland and Luxton, 2005; Christensen et al., 2008; Hall and Wickham, 2008).

Gould (2004), accordingly, regards IMC not a single strategic blueprint but a set of practices and discourses that are dependent on national, organisational, professional, and other cultural contextual contingencies. In line with this perspective, we believe that IMC theorising needs to be more inductive than prescriptive, letting theory evolve by understanding IMC through the eyes of practitioners in their everyday 'practices.' We need studies that look and observe which integrative mechanisms firms actually employ and how these practices are performed. We need to model the underlying structures guiding practitioners in IMC behaviours. 
The purpose of this article, therefore, is to theorise IMC practices relying on Practice Theory as a paradigmatic/metatheoretical as well as methodological tool. Such an approach means additional possibilities to analyse IMC in the field, adding new theoretical tools and language for discussion to the rich empirical data on IMC preferences and implementation practices that have been gathered in different studies in the past. Our practice-theoretical 'gaze' (Whittington, 2007) on IMC would hence be able to ask new types of questions we were unable to ask before. It has the power to make in-depth inquiries about how organisations perform their IMC coordinating functions and uncover the structures that guide practitioners towards IMC.

The contribution of our approach is threefold. (1) A 'Practice Turn' in IMC theorising can offer emic, non-normative understandings of marketing communication integration. Complementing top-down, definitional, normative prescriptions for what constitutes 'good IMC', we suggest to engage with the emic lifeworld of IMC practitioners and their IMC practices. (2) Our work encourages research on new phenomena, which previously fell outside of academic research programs. Invisible and seemingly trivial phenomena such as materiality or routines and their role in integration finally can enter academic discourse. (3) Finally, Practice Theory presents a coherent theoretical and methodological framework to study the above phenomena. As we will show, the increasing sophistication in theorisation, operationalisation and allied methodological tactics to capture practices are extremely valuable to build a systematic understanding of integration.

The structure of the paper is as follows. First, the relevant literature is reviewed in terms of (1) general and applied Practice Theory, (2) its operationalisation for research, and (3) empirical work in the IMC field, which bears similarities to (though not explicit utilisation of) Practice Theory. Second, the methodology of the empirical work conducted is explained. Third, findings are reported in five sections: (1) routines, (2) material set-ups, (3) rules and procedures, (4) cultural templates, and (5) teleoaffective structures. Finally, the results are discussed and implications are drawn for research and practice.

\section{Literature review}

\section{The 'Practice Turn' in the social sciences and organisation studies}

Over the past two decades there has been a growing interest in management practices. Practice Theory has emerged as a framework to study such practices, sweeping across various strands of the social sciences (Duguid, 2005; Reckwitz, 2002; Schatzki et al., 2001), strategy (Feldman and Orlikowski, 2011; Johnson et al., 2007; Whittington, 2006), marketing management (Kjellberg and Helgesson, 2006; Mason et al., 2015; Skålén and Hackley, 2011) and consumer research (Holt, 1995; Schau et al., 2009; Woermann and Rokka, 2015).

The rising popularity of the framework can be traced particularly to its inclusiveness bridging the study of practitioners and organisations, bridging perceptions and behaviours. These qualities include its ability to link individualism and societism, to understand human activity and its social context as communicating vessels. Practice Theory also proposes a framework to understand the relationship between practitioners' behaviours and perceived meanings. As a means to capture the social complexity of everyday life inextricably linked to routines, materiality and tacit knowledge, it has been used to understand a variety of marketing and management related issues, such as how product designs are used by 
consumers (Shove, 2007), how consumer activities in online communities create value (Schau et al., 2009), how coordination is achieved within organisations (Jarzabkowski and Balogun, 2009), how knowledge and innovation is managed (Newell et al., 2009), and how brands are built (Järventie-Thesleff et al., 2011).

Amalgamating works of social theorists (de Certeau, 1984; Giddens, 1984; Lave, 1988), Practice Theory (Latour, 2005) is not simply a (mid-level) theory of practices as the name suggests - but rather a paradigmatic meta-theory married to particular methodological choices: 'a special approach to understand the world' (Feldman and Orlikowski, 2011), a 'gaze' (Whittington, 2007), an 'ontology' (Schatzki et al., 2001).

The Practice Theoretical framework shows growing consensus around some general propositional building blocks, which unite its different streams (Feldman and Orlikowski, 2011). First, the world is essentially a social place, in which actions produce and reproduce social life. Therefore individual actions and sociality are mutually interdependent with, and inseparable from, the context in which they are enacted (e.g. Bourdieu, 1990). Second, Practice Theory rejects the idea of separating cognition from action, individual from institution, determinism from voluntarism (Reckwitz, 2002). Instead, Practice Theory offers a unique lens to observe the interrelation between these notions. Finally, actions and social structures are understood to be mutually constitutive. Individuals are, in this sense, free agents but bounded by the collective knowledge, norms, tacit skills, routines and rules of their social worlds. Individual actors are both shaping and being shaped by, the social structures around them (Schatzki et al., 2001).

Strategies, plans, or management approaches, like IMC, are not merely assets, they are not something that companies 'have', but rather "something that people do" (Johnson et al., 2007 , p. 3). In the case of material objects (such as a plan in the form of a PowerPoint presentation 'deck'), which Practice Theory often foregrounds, the important question to ask is not 'what' these material objects contain, but rather what people 'do' with them and how people interact with them - and most importantly how these material objects shape people's behaviour (or not). Hence, IMC as management practice is not 'given to' or 'adopted by' companies, but rather it is recurrently produced in the everyday activities of practitioners. The distinction between understanding IMC as a predominantly normative construct vs. how it is produced in everyday practices within firms is therefore our fundamental meta-theoretical departure point.

Of relevance for IMC, organisational researchers have, over the years, been interested in how routines and technologies coordinate practitioners across organisations and networks and how these mechanisms emerge and evolve in practitioner interaction (Feldman and Orlikowski, 2011, Jarzabkowski et al., 2012). Planning and implementation have in this respect been shown to deliver integration in a quite multifaceted manner - not mainly in terms of physical outcomes (e.g. strategic plans), but in their functions as processes which bring practitioners together and stimulate negotiation and discussion around shared concepts (Jarzabkowski and Balogun, 2009). Also central to this view is that the mechanisms of coordination and collaboration are socially constructed and socially negotiated in terms of meanings, procedures, and contents. It is the repetition and routinisation that gives them a structural status (Giddens, 1984). Practices also have discursive qualities (Mantere and Vaara, 2008), shaping collective frames and meanings (Bechky, 2003; Kaplan, 2008) and mutual role expectations. 
From a practice-theoretical perspective, practices are 'routinised behaviours' (Schatzki et al., 2001), meaning that they are not random actions, but instead they are repeated and organised by some social or formal rules and conventions. In this sense, they are culturally shared templates that guide our activities (Reckwitz, 2002). Practices are constructed by a set of building blocks; "forms of bodily activities, forms of mental activities, 'things' and their use, a background knowledge in the form of understanding, know-how, states of emotion and motivational knowledge" (Warde, 2005, p. 133).

There have been variations in the ways in which researchers have operationalised these concepts in empirical studies (e.g. Arsel and Bean, 2013; Jarzabkowski and Balogun, 2009; Woermann and Rokka, 2015). Yet, even though the structuring of data may differ, they all depart from the same basic paradigmatic launchpad. That is, in order to study practices we need to see (1) behaviours, in the light of (2) their associated tools, technologies and material artefacts, (3) their procedural knowledge, rules and instructions, (4) their tacit cultural templates, and (5) their ends and perceived objectives, or to use the labels by Schatzki (2002) 'doings', 'things', 'rules', 'understandings' and 'teleoaffective structures'.

For the sake of this study, we will use the following operationalisation for the components of the practice construct:

1. Routines are recurring and often non-reflexive actions and bodily activities of practitioners, which relate to IMC planning practice;

2. Material set-ups are tools and technologies that are central to the execution of these routines;

3. Rules and procedural knowledge recognise the existence of formal instruction, guides, training and rules for performing the practice. They give the IMC practitioner knowledge about 'what should' be done;

4. Cultural templates refer to the contextual, organisational knowledge that is often tacit to its bearer. It is acquired by IMC practitioners as they learn 'how' things are done in the light of the social discourse, including organisational values, norms, history, and culture;

5. Teleoaffective structures, to adopt Schatzki's (2002) conceptualisation, refer to personal understandings of the purposes, ends, emotions, and objectives that drive the activity in question. They can be captured as IMC practitioners' understandings of (and longing for) the reasons 'why' IMC practices are performed.

\section{Practices in prior empirical IMC research}

A substantial number of empirical studies have explored the IMC concept (Ots and Nyilasy, 2015). Whereas these publications have contributed greatly to our understanding of the diffusion of the academic IMC construct in different industries and countries, the accumulated empirical material tends to reside on an aggregate level. Commonly, corporations, industries, and professions are surveyed with regard to their perceptions of IMC and to what extent they claim to apply the associated principles in their operations. Only a very limited number of studies actually make the connection between practitioner 
understandings of IMC and their associated behaviours. In the following literature review, we reflect on the existing empirical knowledge in the field.

Studies of how practitioners understand and adopt (the academic/etic conceptualisations of) IMC. A number of studies can be said to investigate the meanings or perceptions practitioners assign to the academic/etic conceptualisations of IMC. Often these have followed a similar methodological pattern where predetermined definitions (e.g. Kallmeyer and Abratt, 2001) or statements (e.g. Eagle et al., 2007; Kitchen et al., 2004b) are presented to survey respondents, with which they can agree or disagree or which they can rank order, according to relative importance or perceived priorities (Eagle et al., 1999; Kallmeyer and Abratt, 2001; Kitchen et al., 2008). Such propositions commonly include that by adopting IMC, practitioners subscribe to the idea and the benefits of:

- Message consistency in multiple channels (e.g. Beard, 1997; Duncan and Everett, 1993; Nowak and Phelps, 1994);

- Coordinating communications disciplines (e.g. Eagle et al., 1999; Kallmeyer and Abratt, 2001; Kitchen et al., 2004b);

- Consumer-centric thinking (e.g. Kliatchko and Schultz, 2015);

- Directing brand strategy (e.g. Kitchen et al., 2004b; Kitchen et al., 2007; Laurie and Mortimer, 2011);

- IMC as a strategic business process (e.g. Kitchen et al., 2004b; Kliatchko and Schultz, 2015).

The findings of these studies generally confirm that most practitioners associate IMC with message consistency and coordination of communication disciplines, while a smaller proportion sees IMC as a business process. A few additional studies have mapped practitioner perceptions about how IMC should be evaluated and incentivised (Eagle et al., 1999; Kitchen et al., 2008; Swain, 2004).

Though the mere acceptance of the propositions above indicate something about practitioners' relationship to IMC, it is difficult to assess exactly what it means for their daily work. It raises new questions about what procedural and cultural meanings practitioners assign to these predefined, 'etic' utterances and what resides, in contrast, in their emic, everyday actions and lifeworlds.

These studies have often focused on surveying levels of 'IMC adoption' or 'IMC implementation' - the extent to which practitioners claim to enact the proposed principles of IMC. Another way to describe it could be whether they believe that their marketing communications practices are aligned with the normative propositions of IMC. It is difficult to tell "whether there is indeed a wide actual support for and enactment of approaches and practices associated with IMC, or rather just an agreement among marketing managers and agency executives with the rhetoric of IMC and the positive connotations that the term possesses" (Cornelissen, 2001, p. 486). As Kliatchko suggests "there still remains a dearth of research that could ascertain the extent and depth to which IMC is actually practiced in organisations" (2005, p. 13). Some of the explanations given to this lack of emic research is that it is difficult to research IMC since it involves both concepts and processes (Duncan and Everett, 1993), and that these are contextual and will vary from one organisation to the 
next (Kitchen et al., 2008). We see these additional arguments to embrace contextuality rather than searching for universal solutions.

A number of studies have further evidenced that practitioners' professional field of practice seems to matter for their understanding of IMC. Differences have been found between industry thinkers and academics (Laurie and Mortimer, 2011), practitioners in PR and advertising (Kerr and Drennan, 2010; Kitchen et al., 2004b; Rose, 1996), and ad agencies and their clients (Eagle et al., 1999; Eagle and Kitchen, 2000; Swain, 2004). Some studies have also noted that such perceptual and cultural differences among stakeholders can have consequences for the implementation of IMC in organisational processes (Eagle and Kitchen, 2000; Ots and Nyilasy, 2015).

Studies of how practitioners enact (their native/ emic practice of) IMC. No study to our knowledge used Practice Theory explicitly as a theoretical framework to explain IMC in action and within its native, emic context. A number of studies, however, looked at phenomena, which could easily fall under our 'practice theoretical gaze', in that these studies take interest in what practitioners actually do. Though many of the studies only study self-reported, decontextualised behaviour, it is still important to review this literature here.

Starting in the late 1990s, a number of studies set out to explore components of what we consider part of 'practices', as defined above. Gould et al. (1999) used a small scale ( $\mathrm{n}=12)$ mail survey to study the coordinating practices of IMC clients. These practices included the use of various material communication tools (e-mail, phone, fax, etc.), practitioners' efforts in integrating various organisational functions (media planning, media buying, creative), and the existence of various procedural policies to coordinate brand communications. Peltier et al. (2006) described how IMC was combined with database marketing, providing one of the first examples of the phenomena akin to our 'routinisation' and 'material set-ups'. Similarly, Kitchen et al. (2004b) explored a number of aspects of procedural dimensions of IMC in a quantitative survey, when they ventured beyond mere opinions and perceptions by asking advertising and PR agencies whether they actually measured IMC effectiveness, and whether they applied a standardised evaluation metric for IMC.

Dewhirst and Davis (2005), showed in a longitudinal case analysis of Player's cigarette brand marketing, how IMC practices emerged to ensure strategic consistency, relationship building, cross-cultural integration, and data-driven marketing in changing contextual conditions.

Beverland and Luxton (2005) demonstrated, in an ethnographic study, how IMC was practiced by wineries. They found that the outward image was decoupled from their internal IMC practices in order to maintain their brand authenticity being 'wine makers' rather than 'IMC marketing machines'. The authors argued that there was a need for more ethnographic approaches to understand how IMC practices are adjusted to fit local organisational values and needs. Hall and Wickham (2008) showed, in a case study format (including 25 semistructured qualitative interviews), how IMC was implemented at Tasmanian Light Shipbuilding company. The study showcased the role of IMC functions within an industry network. The research identified three context-specific work roles ('IMC Champion', 'Network Ambassadors', and 'Government Lobbyists'), their IMC activities ('information gathering', 'evaluation of past IMC activities', 'information analysis', 'information dissemination', 'network marketing coordination') and their outcomes ('government lobbying', 'IMC programs'). Einwiller and Boenigk (2012) investigated a large sample of 
marketing practitioners in Swiss firms $(\mathrm{n}=642)$. While they did not claim to study IMC practices explicitly, but they developed key indicators of strategic, stakeholder, process, and executional integration. The occurrence of these indicators (which included items such as 'perceived leadership support', and 'existence of scripted communications plans') was then linked to perceived communications performance.

More recently, Patti et al. (in press) studied IMC objective-setting processes. The study let an expert panel interpret a sample of advertising award entries and how the agencies had formulated campaign tasks and objectives in their submitted case descriptions. Kliatchko and Schultz (2015) conducted 22 in-depth interviews with marketing managers, advertising agency heads, and media agency managers studying IMC perceptions and practices. They asked managers to describe how IMC was enacted in practice: (1) how practitioners used multiple media and performed agency coordination, (2) how they based campaigns on consumer insight, proprietary tools for consumer insight, and business analysis, (3) how they implemented brand analysis and communication tactics, budget allocations, and measurement metrics.

\section{Method}

A practice-theoretical study needs rich, contextualised, emic data. In order to study practices in a practice-theoretical sense, we need to sense the context, or the 'site' of the practice (Schatzki, 2005) - in other words, we need to recognise the organisation as an arena where the context and the contextuality of the activities converge.

Research site

Our two-year organisational ethnographic case study collected rich data covering the clientside IMC practices of a large Swedish food retailer within its headquarters in Stockholm. The company was selected based on its multifaceted marketing communications operations in which they claimed to practice IMC. At the time of the study the retailer had annual net sales of 48 billion SEK (roughly equivalent to 5 billion euros) and employed close to 5,000 full time employees. The company was consistently found among the largest advertisers in the country and it had won numerous advertising prizes for its campaigns for creativity and effectiveness.

IMC was an especially suitable object of study at this research site because IMC was claimed by management to be at the core of a range of different practices performed at the marketing department. The retail chain was formed in the early $20^{\text {th }}$ century as a collaboration between independent food retailers and to this day has maintained a structure where the majority of the stores are locally owned. The local ownership and the closeness between the store owner and the customer have always been central to the corporate mission and brand. Store owners influenced not only their own product range and their own local advertising but also the national communication strategies through various retailer forums.

In the firm, marketing communications decisions are made on three different levels. On the national level, brand strategies are developed and managed at the headquarters in Stockholm. On the subbrand level, the stores are divided in four different chains, largely dependent 
upon their size and product range. Each subbrand has its own campaign team and campaign budget. On the local level, store owners and local store networks make their own promotions, which they advertise in newspapers, in local TV, and via direct mail. In sum, the national level is responsible for brand campaigns, whereas the subbrand level and local levels focus on product promotions (see Table 1).

\section{Table 1: IMC decision-making structures}

\begin{tabular}{|l|l|l|}
\hline Organisational level & Operational focus & Main channels \\
\hline $\begin{array}{l}\text { National marketing } \\
\text { department }\end{array}$ & Master brand & - TV advertising \\
\cline { 2 - 3 } Subbrands & CRM & $\begin{array}{l}\text { - Customer magazine } \\
\text { - Online }\end{array}$ \\
\hline Local stores & Promotional campaigns & $\begin{array}{l}\text { - Outdoor advertising } \\
\text { - In-store promotions } \\
\text { - Unaddressed DM } \\
\text { - Personalised DM }\end{array}$ \\
\hline & Promotional campaigns & $\begin{array}{l}\text { - Newspaper advertising } \\
\text { - Unaddressed DM } \\
\text { - Personalised DM }\end{array}$ \\
\hline
\end{tabular}

In 2000, the company started collaborating with a new advertising agency, and in 2001 they launched a new creative concept for TV advertising, which proved to be hugely successful. Where earlier retail advertising focused on displaying promotional offers and putting the suppliers' product brands in the foreground, the new advertising concept focused on building the retailer's own brand by embedding the promotional content in a comic soap opera that centred on daily life in a fictitious food store. At the centre was the friendly store owner and his rather eccentric staff. The TV-concept, which was still running in 2015, was been novel to the audience as it had a good cast, high production budget, high entertainment value and unfolded a continuously evolving plot in weekly episodes where the audience became familiar with the characters over time. The concept was an immediate success gaining wide advertising recall and transforming brand attitudes fundamentally. In essence, the brand was perceived as more likeable and attractive both for customers and potential employees. The achievement was recognised in the industry winning multiple awards for both creative excellence and advertising effectiveness.

The success of the national creative concept brought IMC in the focus. Though TV advertising was gaining the bulk of attention it only accounted for around $10 \%$ of the total marketing communications budget. The majority of ad spending still went to direct mail and newspaper advertising. The retailer also had a large internet operation including a popular database for food recipes and it produced the most circulated customer magazine in the country.

Top management claimed to practice IMC but considering the decentralised and complex decision-making structure, the size of the multifaceted operations ranging from food retailing to banking services and media publishing, and the involvement of multiple external agencies, in addition to a large in-house agency, the practical organising of IMC appeared challenging. 
Gaining top management support provided access to both individual professionals and many of their mutual activities and meetings. Over a period of 25 months, the planning, execution, and evaluation of the IMC cycle was followed as it unfolded. Data was collected on 24 different points of interaction with 15 client-side marketing managers ranging from the top marketing director to market analysts, campaign managers, and project managers.

Data collection and analysis followed the principles of organisational ethnography (Arnould and Price, 2006; Van Maanen, 1988; Zickar and Carter, 2010) and case study methodologies (Eisenhardt, 1989; Piekkari et al., 2010; Yin, 2006).

The IMC campaign as a whole formed the boundaries of the ethnographic case data collection in time and space, within which different types of data were collected - semistructured interviews (face-to-face and on the telephone), participant observations, as well as archival imprints of e-mail correspondence, meeting protocols, strategy documents and evaluation reports.

Semi-structured interviews lasted on average 90 minutes, were digitally recorded and transcribed verbatim. Participant observations provided further insights into how practices were enacted in IMC planning sessions, strategy meetings, agency briefings, and media negotiations that involved multiple practitioners. These were recorded and reflected upon in fieldnotes. Archival material (of e-mail correspondence, meeting protocols, and strategy documents) was collected under confidentiality agreements not to disclose specific, verbatim quotes, only structural information on practices.

The corpus was entered into qualitative data-analysis software, NVIVO. Coding used the constant-comparative method (Corbin and Strauss, 2008), continuously going back and forth between the emerging practice-theoretical themes and the data. As discussed above, operationalisations of Practice Theory in organisation studies provided a broad framework in this sense, our version of constant-comparative coding was a combination of deductive and inductive ideas, following the suggestions of Burawoy (1991). Coding comprised of various steps. As a first step, we used open coding identifying general themes (e.g. practices in general, all non-declarative, hidden, routinised references to IMC planning and implementation activities). Later, and in consultation with existing operationalisations of different types of practices (e.g. Schatzki, 2002), we conducted selective/axial coding (Corbin and Strauss, 2008) and developed the five elements of practice reported in the findings (routines, material set-ups, rules and procedures, cultural templates, and teleoaffective structures). We constantly compared these themes in the entire data corpus until saturation.

\section{Findings: IMC as practice}

The following empirical exposition deconstructs IMC enactments from a Practice Theory vantage point. The resulting material illustrates how IMC as a practice is constituted by (1) routines, (2) material set-ups, (3) rules and procedures, (4) cultural templates, and (5) teleoaffective structures. Going beyond IMC as production and implementation of a topdown, normative plan, we will here discuss IMC as a set of integrative practices, aligning various stakeholders' diverse behaviours and knowledge forms. Specifically, we want to 
exemplify how such practices enact the integration of channels, disciplines and stakeholders within the objectified and materialised professional action of IMC.

\section{Routines}

The marketing communications process followed a routinised sequence of activities. Starting the annual planning cycle in January, the National Marketing Communications Manager gathered his work group of analysts, brand managers, and campaign planners (for a schematic overview of the emergent planning routines, see Figure 1).

Figure 1: The emerging flow of IMC planning routines

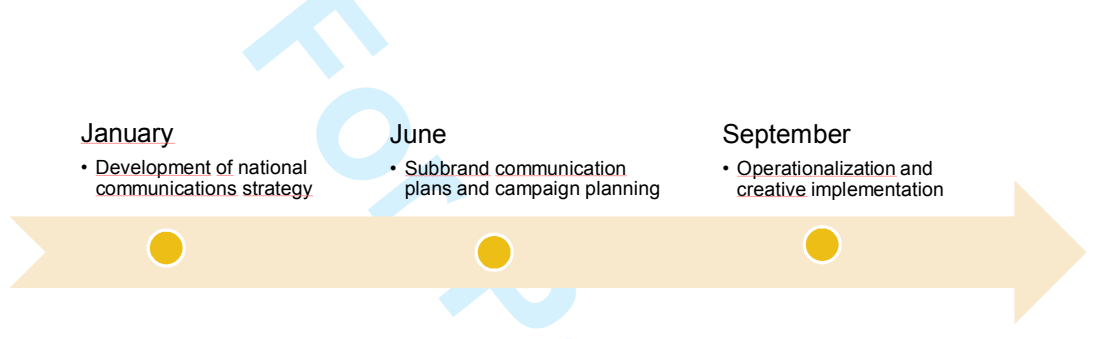

Source: Archival materials.

Like many similar processes the work started with business intelligence. Quantitative and qualitative consumer data, consumer shopping trends, brand development and past campaign performances were accumulated, evaluated, and analysed to form the basis for the forthcoming national communications plan (Fieldnotes). This included a series of meetings and hearings with analysts, agencies, and representatives from different internal departments and communications disciplines. In these routines, evidence supporting the emerging strategy was accumulated and compiled (and thus materialised) into various reports and PowerPoint presentation 'decks', which were presented and shared within the work (Observations and archival materials).

By March, the background data had formed the basis of a thematic plan that outlined the overarching structure in terms of focus areas to be emphasised in strategy for the coming year. This plan was then presented to the Operative Marketing Management Board (MLG) a group which contained leaders with formal power as well as cultural capital in various disciplines within the organisation. On approval from MLG, the workflow continued to develop a specific set of positioning attributes, on which the brand was perceived to be needing improvement. During this phase the work was also coordinated with the creative agency and the parallel plans developed by the CRM team and the content marketing agency. The resulting positions were visualised by draft creative ideas from the strategic advertising agency. The resulting information then was compiled into yet another master document labelled the 'Communications Plan', which was ultimately tested when presented to the Market Council Sweden (MRS) (Archival materials). This forum represented a range of internal stakeholders, notably, store owner representatives and marketing managers for all the sub brands. The young work group within the marketing communications team was 
undoubtedly skilled at analysing and planning, but admitted that it was a different thing to challenge the store owners' collective experience of practical retail management in attempts to convince them about the value of brand development and executional consistency.

After approval from MRS, the communications plan was operationalised. It was broken down into communications plans for the four store chains, weekly promotional campaigns and the work of the purchasing/campaign organisation started to initiate negotiations with suitable suppliers (Observations).

In the third and final phase starting in September, briefs were sent out to the creative agency, the media agency, and the internal agency. During the last three months of the year, things started to move quickly, advertising media was bought for the full coming year, production of TV ads started, and publishing plans were rapidly finalised.

\section{Material set-ups}

Partially hidden from view, in the above IMC routines, objects, such as computer software, played crucial roles as both enablers and ironically, barriers of integration. Managers described how IMC-strategizing did not start with a blank canvas. On the contrary, each year's strategy departed from an Excel sheet listing all media channels to be used by week, which then had to be filled with promotional campaign content (Fieldnotes). In this sense, both the timing and the channels of communication were predetermined in the materiality of a pre-existing grid, removed from future debate and ad-hoc strategic deliberation. The Excel sheet itself, as a material set-up, was forcing channel integration upon the planners and others involved in the planning routine. While it did not specify the message to be conveyed, it set firm boundaries around what was possible. Once objectified, it was not possible to question the framework manifested in the Excel sheet (Archival materials). The grid was it.

When each year starts we know that we will use TV. Our job in this process is substantiating it by defining wbich way and why. (Marketing Communications Manager 1)

In this sense, also, the media channels were objects that actively shaped the strategy process rather than the other way around. And the retailer had lots of them.

Our media plan contains a classic dilemma. We happen to own so much media ourselves that we don't choose communication tools according to task. Rather, we choose the tools first and then the plan becomes the outcome of the tools that we must use. (Marketing Communications Manager 2)

The pre-structured Excel sheets were also creating a particular kind of integration that gravitated towards cross-media standardization of designs and formats for flyers, newspaper advertisements, in-store materials and other campaign media (Archival materials, observations). It ensured that messages and promotional offers were synchronised across weeks and media channels, but as the National Marketing Director noted, channels which did not fit in the Excel sheet tended to be difficult to integrate (Fieldnotes). This included the web portal, the customer magazine, and other media which simply did not have a predetermined rubric in the weekly campaign structure.

At the same time, objects like PowerPoint decks, Excel sheets, measurement tools, TV-ads and internet websites, also carried the power to achieve deeper stakeholder integration. In 
this view, marketing channels were regarded as tools that produced IMC practice, rather than being mere residuals of IMC planning. In particular, TV ads had integrating capacities informing employees and store owners about ongoing campaigns and ensuring engagement and better implementation, while spreading brand values. The customer magazine was similarly recognised as a tool that stimulated store owners to constantly renew and innovate their product range in order to enliven the brand value of 'food inspiration' (Fieldnotes).

\section{Rules and procedures}

Whereas most of the involved practitioners had an idea about what IMC theoretically 'ought' to be, it was also clear that the organisational particularities added a lot of complexity to practitioners' procedural understandings of how this was to be practically conducted (Observations).

Managers as well as other stakeholders testified that the procedural dimension of planning was unusually strong at the retailer. Planning started at least one year (in some cases close to two years) in advance of actual campaign execution. The process was strict in terms of the contents and sequence of the different steps that had to be undertaken. It was noted that the process was not set up according the text-book version of IMC planning (Archival materials, fieldnotes). Whereas the practitioners were in one sense free to come up with new creative communications ideas and strategies for the organisation, it was also clear that the practitioners experienced practical boundaries on this freedom. Rather than putting the emphasis on developing communications strategy, the procedure emphasised the tactical and operative dimension, practitioners described it as 'mechanical' or 'rule-like'.

There is an incredible number of mechanics in the company's communication planning. You don't really see that from the outside, but there are an incredible number of goods that need to go along with our communications. We basically show promotional prices. A lot of 'prices-and-products', 'prices-and-products' combinations... (Marketing Communications Manager 1)

The background to this was the co-op advertising environment, which is central to many retail chains, where suppliers effectively sponsor a large share of the advertising media costs in exchange for campaign exposure for their products. As a result, the retailer was annually attracting hundreds of millions SEK from suppliers - internally called 'market money' -, and these funds were funnelled down to store owners and subbrands. It was widely understood that these monies were the foundation on which the retailer had built up the largest media eco-system in the country, containing customer media, internet sites, TV-ads, in store media, direct marketing, and loyalty clubs (Fieldnotes, archival materials). These procedures and mechanisms were perceived to be deeply rooted, not only in this particular organisation, but in the retailing sector at large.

This industry has been working the same way since the 1960s, to be a bit harsh... The food retailing industry knows this, and the suppliers know this. They were raised with this. Everybody who has studied at university has heard about it at some point. And that's the way it works - it isn't any barder than that. (CRM Manager)

Each week, all these channels had to be filled with new content in the form of promotional offers. The marketing managers thus described their understanding of the program on two levels: that of the weekly promotional 'campaigns' and that of the longer-term 'brand 
themes' (Fieldnotes). At the 'campaign level' the calendar year was divided into weekly promotional campaigns that featured different product offers. For each week of the coming year, the retailer needed to fill their predetermined media plan of TV ads, direct mails, and loyalty mailings, in all their four store chains with a set of attractive promotional deals. Clearly, the strategic plan was to a great extent recognised as a product of the procedure, not the other way around.

On a scale from 1-10, I'd say I have a 4 in my ability to influence the process. If fou had a 10 million keronor media budget when you walk into a company then you wouldn't buy media the way we do here. (Marketing Communications Manager 2)

There is something particular about food retailing since there is such an incredible amount of money involved. I don't think there is any company in Sweden with a comparable marketing budget if we look at our organisation as a whole. But we only control... maybe one sixth of it. That we can truly manage. The other five sixths just... they just live their own life, managing themselves. (Marketing Communications Manager 2)

\section{Cultural templates}

The marketing communications planning process was marked by two different cultural templates. On the one hand, the broad cultural understanding in the firm regarded the retailer as a sales organisation, owned by the retailers, where product sourcing and the everyday operational work carried out in the stores were perceived to be the core activity. Despite the self-perception of being a 'modern marketing organisation', with a range of communications skills represented at the headquarters, the heritage of being founded as a joint purchasing service for independent stores (and thus essentially being a supply chainand operations-driven business) was still strong (Observations, fieldnotes). Even within the personalised corporate brand image, in the form of the creative TV advertising concepts described above, the store owner was the central character.

What is unique about our company is the entrepreneurship. If we compare ourselves with our competitors, then this really stands out. A lot of things, not only on the store floors, but also among people working throughout the organisation, are driven by this perspective. [...] The fact that our CEO started off as a local store owner tells a whole lot. We are driven by a customer focus. And that's an incredible strength. (National Brand Manager)

A practical consequence of this cultural orientation was the constant highlighting of sales promotional materials, short-term weekly campaigns and operational efficiency in all IMC activities. Even IMC itself was perceived as predominantly being a subset of the supply chain sourcing process, only for communication media (Fieldnotes). This cultural template (only partly explicit and more of a tacit, cultural understanding among participants) was shared among store owners in the Market Council Sweden (MRS), who had to eventually approve all IMC planning and materials (Observations, archival materials).

On the other hand, there was the growing understanding of communications planning to be a branding process. Within this cultural template, marketing communications had a longterm vision that embraced creativity, understanding of customer relations to the national brand, beyond the local store. In particular, the National Marketing Director, who had been recruited from a global fast-food chain, was driving the development towards larger, brand- 
building campaigns. Against this background, marketing communications planning was a strategic and creative process.

I think this change is a result of a lot of things - an organisational learning process that all these small campaigns do not pay off, consultants saying that they should do things differently, and of course a marketing director who has this way of thinking in his backbone. (Media Strategist)

\section{Teleoaffective structures}

Teleoaffective structures are practices that express ends and objectives inextricably linked to emotional status (such as longing or wishful thinking) towards achieving those goals (Schatzki, 2002). In the context of IMC, our data showed that practitioners held somewhat contradictory understandings about the ends and objectives of the IMC planning process.

On the one hand, seen as a part of the sourcing process, objectives were often stated in terms of filling the media machinery with weekly content (products information and promotional offerings), and in that process bringing in 'market money' from the suppliers. Suppliers, similarly, on their side, had the short-term objectives of getting their products exposed in the stores, enwrapped in procedures and materialised routines, which turned out to be rather rigid and difficult to change.

For the individuals working with supplier sales, changes to this system might also produce changes on a very personal level. They might think, I might lose my job - and my job is to do the negotiation for product and price for each campaign period. (CRM Manager)

On the other hand, as a means of achieving improved integration and consistency, marketing managers were passionately claiming that the planning process also served the objective of building brand equity (Observations, fieldnotes). This teleoaffective structure, being ripe with positive emotions (longing and wishing for an idealised brand state of positive consumer attitudes and involvement) was supported by goal-driven brand tracking conducted for all media. Brand tracking was carried out weekly after each TV ad was aired, assessing the likeability of the characters, advertising recall, and brand awareness (Archival materials). The same metrics were employed for the assessment of the other branding channels throughout the organisation such as customer magazines, internet sites, and mobile platforms. Results were circulated in internal reports, presentations, in financial statements and in the evaluation of the performance of the communications working units (Archival materials). The outcomes were enwrapped in an increasingly standardised language for valuing marketing communications, not in terms of campaign sales alone, but in terms of its (mostly emotively understood) communicative powers. The outcomes also served the emotional needs of managers, realising wishful thinking relating to an emotively imagined, engaging brand and their own status as 'modern marketers' orchestrating it, in tune with consumer sentiment (Observations, fieldnotes).

An emerging challenge was the insight that these two objectives had to meet in the marketing communications planning practice. There was a need to develop a shared understanding for brand development while maintaining sales and supplier involvement. In various meetings throughout the organisation, the marketing team knew that they had to bridge the cultural differences between stakeholders (Observations, fieldnotes). 
It is often neglected, that in a system like this, if you already have managed to sell the campaign objective internally, so that the store owners feel like "wow, this is good", then you are already halfway there... Because they will then make sure that all this is executed well in the stores. It also works the other way, that if you have failed to sell the objective internally, then you may have a great creative idea, backed up with lots of advertising media, but you will fail anyway. (National Marketing Director)

In other words, a purely top-down IMC process would not have succeeded in this organisation. Strategic IMC planning was, in this sense, an integrative activity. It served not only to produce a plan as an output, but it also 'produced' the process itself of negotiating stakeholder objectives and goals (for a similar discussion, see Jarzabkowski and Balogun, 2009). To the managers it became increasingly evident that the planning practice itself was an arena for achieving stakeholder integration.

We could be much better at optimising the business as a whole. But we have 15 tools that need to go into the plan. I was in a forum with marketing managers who said "maybe you could plot in all your media tools just so we know what we are talking about". Damn, it took two hours. But that was the first time we really started to discuss, what roles do direct mails and other media play? And then we realised that most of the time we just kept on doing things like we always had. And that was a quite terrible realisation, to be frank. (Campaign Manager)

This process of integration was not unidirectional, but an ongoing dialogue, creating increased reflexiveness about the organisation and its unique context.

Now we have realised that even if we have strong advertising and marketing, the real action happens somewhere else. We have store owners who meet the customers every day, and they have made sure we don't forget that.... Which happens in other organisations, I believe. It is easy to lose contact with reality, and miss this concrete feedback from those who meet the customers every day. (National Brand Manager)

\section{Discussion \\ General discussion}

In this study, we have introduced a Practice Theoretical gaze on IMC with the aim of extending the theoretical conceptualisation on IMC - in particular, its manifestations in business practice. From this perspective, practices are more than individual activities or structural plans - they are best understood as an interwoven network of routines, objects, processes, cultural templates, and emotionally charged goals.

The findings increase the complexity and nuance of understanding what it means to 'do' IMC, adding elements of context, learning, interaction to the picture. Findings have elements that may appear counterintuitive or 'backwards' from the more normative view on IMC. However, by understanding this complexity, we also see that the seemingly suboptimal elements of practice, indeed, had meaning in practitioners' lived experience.

Routines are a critical part of IMC practice. They are, for the most part, taken for granted and trivial for the non-reflexive observer. Yet, routines encode both the particular ways in which integration takes place in a marketing organisation and also the ways in which it may run astray. In the case of our Swedish retailer, enacting IMC planning was heavily routinised into 
sessions and workflow, which helped to achieve consistency and strategic commonalities, but at the same, these routines choked off creative and spontaneous discussions and the freedom to choose strategic avenues that could have been even more productive.

Material set-ups, are the physical manifestations of IMC in the forms of media planning computer software, PowerPoint presentations, Excel sheets, etc. They have a similarly 'invisible' and yet constitutive role in getting IMC done to routines. Material set-ups both allow and delimit choices. In this sense, they have the power to force particular forms of IMC onto the organisation, but can also act as barriers to others. For example, PowerPoint decks have the ability to communicate ideas, share objectives, and orchestrate a socially constructed consensus of what integration means in the context of a particular campaign. Excel media flowcharts and media planning software can optimise integrative solutions but only insofar as media ideas can be force-fitted into the pre-determined IMC rubrics available.

Rules and procedures are more matter-of-fact elements of practice and by definition declarative and factual. The idea of IMC as strategy-making was in many cases procedurally reduced to mere process coordination and administration. Procedures proved to be very important for IMC planning but they emphasised only some parts of integration - channel and message coordination. They played a key role in making the IMC system manageable - but at the expense of being rather strict forms of standardisation for communication content. The output was a 'formatted' version of IMC.

Cultural templates are practice elements which often carry subtle and tacit forms of socially constructed meanings about IMC planning. The retailer struggled with an inherent drama around two tacit cultural themes governing the organisation. On the one hand, the legacy of an operations- and sales-driven cultural template determined IMC decisions. On the other hand, the modern marketing organisation investing in customer-centric branding served as a competing cultural theme. These two opposing templates often clashed, preventing successful IMC implementation - either directly, or in interaction with other IMC practice elements, such as routines, procedures and materiality.

Finally, teleoaffective structures were also observed. They manifested themselves in the often conflicting objectives declarations of: "we need to achieve stakeholder integration", "we need to create Target Ratings Points", "we need to sell products", "we need to produce a good magazine," "we need to fill the campaigns" (Archival materials). While teleoaffective structures were constitutive in achieving integration by orchestrating consent around mutual goals (creating "stakeholder agreement"), they also carried the emotional imprints of managers pursuing their affective agendas of being a "brand champion" or "captain of sales" (Fieldnotes, observations). Further, teleoaffective structures were objectified in the material setups of metrics tools. Measurements, metrics, brand tracking were ways to visualise, communicate and celebrate progress and achievement, even if they were directly linked to short-term sales.

\section{Implications for research}

For future academic research, the main contribution of the Practice Theory approach exhibited in this paper is threefold. A 'Practice Turn' in IMC theorising can offer (1) emic, 
non-normative understandings, (2) research on new phenomena, and (3) a coherent theoretical and methodological framework for explaining these phenomena.

First, a Practice Theory-based approach allows researchers to complement top-down academic ideas of what IMC is and what it 'should be' with grounded, emic understandings of IMC among practitioners. Those practicing IMC are both creating and created by their lifeworlds of marketing activity, where individual mental maps blur with structural features of the environment encompassed in cultural templates, materiality and routinisation. If one does not see much adoption of academic conceptualisations of what IMC 'should be', one 'should not be' surprised. IMC managers enact 'knowledge autonomy' (Nyilasy and Reid, 2007) and at the same time are bound by practical limitations encoded within their immediate social/material work environment. This mental and social/material environment, however, hardly contains (even indirectly) any academic conceptualisations of IMC, beyond, perhaps, a broad and fuzzy dictate that 'integration is good'. Therefore, a complete (and useful) theory of IMC, by necessity, needs to contain theoretical understandings of what happens in its practical 'use'. More importantly, research needs to realise that it is not 'use' of an external conceptual tool that should be the subject of such studies, rather the emic, lived, material-social experience of practitioners that is 'already there'.

Second, opening up the emic in IMC via Practice Theory allows researchers to study hitherto 'invisible' phenomena, such as implicit routines and tacit cultural understandings. These may seem trivial and counterproductive to dwell on from the perspective of a topdown normative understanding of what 'idealised IMC' should be. However, the seemingly subtle phenomena captured by Practice Theory often have very real outcomes on business performance (Ots and Nyilasy, 2015). Such phenomena are also fascinating from an intellectual standpoint. The materiality of organisations, for instance, is turning out to be the next big wave of organisation studies theory (Hardy and Thomas, 2015). Future research could specifically target, for example, the information technology environment within which IMC practices are enwrapped. With the continuing advancement of big data solutions applied to the optimisation of marketing communications, in fact, such a critical assessment seems absolutely necessary. Similarly, the ongoing deconstruction of the 'tacit' in IMC (let it be routines in which it is expressed or cultural biases it may carry among different stakeholders) seems a fruitful avenue for future research.

Third, a 'Practice Turn' in IMC theorising allows researchers to explain the above phenomena in a coherent framework and new methodological tools. Practice Theory has the great advantage of overcoming outdated dichotomies of individual vs. communal, agency vs. institutionalisation, cognition vs. behaviour, and culture vs. structure. Practices straddle these dichotomies. Further, practices of different kinds (routines, cultural templates, materiality, etc.) are inextricably intertwined. The beauty of deconstructing subtle and implicit strands of practices (via new practice-capturing methodological tactics) is that one inevitably starts to disentangle yet another strand. Yet, the whole stands as a far richer model of social reality in the context of organising for IMC than any siloed psychological, economic, or sociological explanations would in themselves. 
Practice Theory is inherently practical - and this is not simply a pun. While originating in 'high' social theory, we envision its application to IMC to have very pragmatic outcomes for practicing marketing and communication managers as well as strategic partners, such as advertising agency practitioners. To be ambitious, our findings should be applicable beyond IMC: to the broader marketing mix and indeed, marketing's strategic integration into other corporate functions (finance, operations, $\mathrm{HR}$, etc.).

A first step in the direction of better IMC practice is an understanding of what gets practiced in the first place. While we know IMC implementation often gets hindered by issues in organisational structure, organisational culture, operational processes, individual behaviour and mental models, communication, economics, IT and infrastructure (Ots and Nyilasy, 2015), disjointed accounts of these theoretical silos often fail to provide real solutions to practical problems. Practices, on the other hand, bridge individual psychology with organisational structure, cognition with action, and organisational culture with materialities, such as infrastructure and IT (as argued above). Therefore, a structured mapping of IMC practices in a marketing organisation has the promise of integrated and not disjointed implementation solutions.

A second step is understanding what the often implicit practices mean in terms of their effects on important outcomes. Many misunderstandings around IMC implementation arise from the fact that subtle biases remain hidden. For example, media planning software may invisibly bias IMC solutions towards certain types of media optimisation, which may highlight the use of strategically irrelevant media vehicles while suppressing strategically crucial ones. This problem remains 'invisible' because of the taken-for-grantedness of many material/objectified solutions - unless someone specifically problematises their use. Practice theory introduces a new language to express what was before very difficult to articulate and thus allows managing things which were previously unmanageable. Recognizing the role of practices as arenas for interaction where practitioners can communicate and negotiate their tacit understandings of IMC, opens up new possibilities for improving its implementation.

The third step is understanding how practices are interconnected. As we suggested above, even our operationalisation of practices into distinct strands is artificial in the sense that in reality they are all inextricably linked. Therefore, it is critical for IMC managers to understand not only the different types of IMC practices at play (such as routines, materiality, processes, cultural templates, and teleoaffective structures) but also how they are enwrapped and encoded into one another.

A final step is figuring out ways to nudge practices in the direction of better outcomes. Practices, even if perceived as dysfunctional, trivial or being a distraction are never going to 'go away' - no matter how hard top-down, normative directives are forced upon the organisation. It is better to subtly move them in directions that promise better functioning. Cultural templates of branding and sales orientation will always remain, for instance, antagonistic. Yet, as we have shown, practices in teleoaffective structures such as objective setting metrics definitions allowed the coexistence and celebration of both of these cultural orientations in the firm. Further, tweaks and transparency around the underlying objectifying practices of setting-up materiality (in the form of Excel templates for media planning/buying and Measurement and Learning plans for marketing metrics, for instance) 
carry the possibility of relaxing the 'grip of the grid' for more creative IMC implementation solutions around mutually agreed on strategies.

\section{Conclusion}

We believe Practice Theory has a great promise for IMC because it allows us to speak about phenomena, about which, thus far, we struggled to speak. We are able to bring into theoretical dialogue what IMC practitioners have been viscerally experiencing in their socially constructed, lived, dynamic lifeworlds at work all along. We have a language to talk about matters in IMC implementation, which used to be, though immediately understood in practice, silent and silenced in academic discourse. Now that we can, it is imperative that we do speak about practice - even in the form of peer-reviewed academic research articles. To paraphrase Wittgenstein, 'What now can be said cannot remain unsaid.' 


\section{References}

Arnould, E.J. and Price, L.L. (2006), "Market-oriented ethnography revisited", Journal of Advertising Research, Vol. 46 No. 3, pp. 251-62.

Arsel, Z. and Bean, J. (2013), "Taste regimes and market-mediated practice", Journal of Consumer Research, Vol. 39, No. 5, pp. 899-917.

Beard, F. (1997), "IMC use and client-ad agency relationships", Journal of Marketing Communications, Vol. 3, No. 4, pp. 217-230.

Bechky, B.A. (2003), "Sharing meaning across occupational communities: the transformation of understanding on a production floor", Organisation Science, Vol. 14, No. 3, pp. 312-330.

Beverland, M. and Luxton, S. (2005), "Managing Integrated Marketing Communication (IMC) through strategic decoupling", Journal of Advertising, Vol. 34, No. 4, pp. 103116.

Bourdieu, P. (1990), The Logic of Practice, Polity, Cambridge, UK.

Burawoy, M. (1991), "Reconstructing social theories", in Burawoy, M. (Ed.), Ethnography Unbound: Power and Resistance in the Modern Metropolis, University of California Press, Berkeley, CA, pp. 8-27.

Christensen, L.T., Firat, A.F. and Torp, S. (2008), "The organisation of integrated communications: toward flexible integration", European Journal of Marketing, Vol. 42, No. 3, pp. 423-452.

Corbin, J. and Strauss, A. (2008), Basics of Qualitative Researcb: Techniques and Procedures for Developing Grounded Theory, Sage, Thousand Oaks, CA.

Cornelissen, J.P. (2001), "Integrated marketing communications and the language of marketing development", International Journal of Advertising, Vol. 20, No. 4, pp. 483498.

Cornelissen, J.P. and Lock, A.R. (2000), "Theoretical concept or management fashion? examining the significance of IMC", Journal of Advertising Research, Vol. 40, No. 5, pp. 7-15.

De Certeau, M. (1984), The Practice of Everyday Life, University of California Press, Berkeley, CA.

Dewhirst, T. and Davis, B. (2005), "Brand strategy and Integrated Marketing Communication (IMC)", Journal of Advertising, Vol. 34, No. 4, pp. 81-92.

Duguid, P. (2005), " 'The art of knowing': social and tacit dimensions of knowledge and the limits of the community of practice", The Information Society, Vol. 21, No. 2, pp. 109118.

Duncan, T.R. and Everett, S.E. (1993), "Client perceptions of integrated marketing communications", Journal of Advertising Research, Vol. 33, No. 3, pp. 30-39.

Eagle, L., Kitchen, P., Hyde, K., Fourie, W. and Padisetti, M. (1999), "Perceptions of integrated marketing communications among marketers and ad agency executives in New Zealand", International Journal of Advertising, Vol. 18, No. 1, pp. 89-119.

Eagle, L. and Kitchen, P.J. (2000), "IMC, brand communications and corporate cultures", European Journal of Marketing, Vol. 34, No. 5/6, pp. 667-686.

Eagle, L., Kitchen, P.J. and Bulmer, S. (2007), "Insights into interpreting Integrated Marketing Communications: a two-nation qualitative comparison", European Journal of Marketing, Vol. 41, No. 7/8, pp. 956-970.

Einwiller, S.A. and Boenigk, M. (2012), "Examining the link between integrated communication management and communication effectiveness in medium-sized enterprises", Journal of Marketing Communications, Vol. 18, No. 5, pp. 335-361. 
Eisenhardt, K.M. (1989), "Building theories from case study research", Academy of Management Review, Vol. 14 No. 4, pp. 532-50.

Feldman, M.S. and Orlikowski, W.J. (2011), "Theorizing practice and practicing theory", Organisation Science, Vol. 22, No. 5, pp. 1240-1253.

Giddens, A. (1984), The Constitution of Society: Outline of the Theory of Structuration, University of California Press, Berkeley, CA.

Gould, S.J. (2004), "IMC as theory and as a poststructural set of practices and discourses: a continuously evolving paradigm shift", Journal of Advertising Research, Vol. 44, No. 1, pp. 66-70.

Gould, S.J., Lerman, D.B. and Grein, A.F. (1999), "Agency perceptions and practices on global IMC”, Journal of Advertising Research, Vol. 39, No. 1, pp. 7-20.

Hall, L. and Wickham, M. (2008), "Organising IMC roles and functions in the business-tobusiness network environment”, Joumal of Marketing Communications, Vol. 14, No. 3, pp. 193-206.

Hardy, C. and Thomas, R. (2015), "Discourse in a material world", Journal of Management Studies, Vol. 52, No. 5, pp. 680-696.

Holt, D.B. (1995), "How consumers consume: a typology of consumption practices", Journal of Consumer Research, Vol. 22, No. 1, pp. 1-16.

Hutton, J.G. (1996), "Integrated Marketing Communications and the evolution of marketing thought", Journal of Business Research, Vol. 37, No. 3, pp. 155-162.

Jarzabkowski, P. and Balogun, J. (2009), "The practice and process of delivering integration through strategic planning", Journal of Management Studies, Vol. 46, No. 8, pp. 12551288.

Jarzabkowski, P.A., Lê, J.K. and Feldman, M.S. (2012), "Toward a theory of coordinating: creating coordinating mechanisms in practice", Organisation Science, Vol. 23, No. 4, pp. 907-927.

Johnson, G., Langley, A., Melin, L. and Whittington, R. (2007), Strategy as Practice: Research Directions and Resources, Cambridge University Press, Cambridge, UK.

Järventie-Thesleff, R., Moisander, J. and Laine, P.-M. (2011), "Organisational dynamics and complexities of corporate brand building: A practice perspective", Scandinavian Journal of Management, Vol. 27, No. 2, pp. 196-204.

Kallmeyer, J. and Abratt, R. (2001), "Perceptions of IMC and organisational change among agencies in South Africa", International Journal of Advertising, Vol. 20, No. 3, pp. 361380.

Kaplan, S. (2008), "Framing contests: strategy making under uncertainty", Organisation Science, Vol. 19, No. 5, pp. 729-752.

Kerr, G. and Drennan, J. (2010), "Same but different: perceptions of Integrated Marketing Communication among marketing communication partners in Australia", Journal of Promotion Management, Vol. 16, No. 1/2, pp. 6-24.

Kerr, G., Schultz, D., Patti, C. and Kim, I. (2008), “An inside-out approach to integrated marketing communication", International Journal of Advertising, Vol. 27, No. 4, pp. 511548.

Kitchen, P.J., Brignell, J., Tao, L. and Spickett-Jones, G. (2004a), "The emergence of IMC: a theoretical perspective", Journal of Advertising Research, Vol. 44, No. 1, pp. 19-30.

Kitchen, P.J. and Burgmann, I. (2010), "Integrated marketing communication", available at: http://dx.doi.org/10.1002/9781444316568.wiem04001 (accessed November 10, 2015).

Kitchen, P.J., Kim, I. and Schultz, D.E. (2008), "Integrated Marketing Communications: practice leads theory", Journal of Advertising Research, Vol. 48, No. 4, pp. 531-546. 
Kitchen, P.J., Schultz, D.E., Kim, I., Han, D. and Li, T. (2004b), "Will agencies ever "get" (or understand) IMC?”, European Journal of Marketing, Vol. 38, No. 11/12, pp. 14171436.

Kitchen, P.J., Spickett-Jones, J.G. and Grimes, T. (2007), "Inhibition of brand integration amid changing agency structures", Joumal of Marketing Communications, Vol. 13, No. 2, pp. 149-168.

Kjellberg, H. and Helgesson, C.-F. (2006), "Multiple versions of markets: multiplicity and performativity in market practice", Industrial Marketing Management, Vol. 35, No. 7, pp. 839-855.

Kliatchko, J. (2005), "Towards a new definition of Integrated Marketing Communications (IMC)", International Journal of Advertising, Vol. 24, No. 1, pp. 7-34.

Kliatchko, J.G. (2008), "Revisiting the IMC construct", International Journal of Advertising, Vol. 27, No. 1, pp. 133-160.

Kliatchko, J.G. and Schultz, D.E. (2015), “Twenty years of IMC”, International Journal of Advertising, Vol. 33, No. 2, pp. 373-390.

Latour, B. (2005), Reassembling the Social: An Introduction to Actor-Network-Theory, Oxford University Press, Oxford, UK.

Laurie, S. and Mortimer, K. (2011), “'IMC is dead. long live IMC': Academics' versus practitioners' views", Journal of Marketing Management, Vol. 27, No. 13-14, pp. 1464 1478.

Lave, J. (1988), Cognition in Practice: Mind, Mathematics and Culture in Everyday Life, Cambridge University Press, Cambridge, UK.

Mantere, S. and Vaara, E. (2008), "On the problem of participation in strategy: a critical discursive perspective", Organisation Science, Vol. 19, No. 2, pp. 341-358.

Mason, K., Kjellberg, H. and Hagberg, J. (2015), "Exploring the performativity of marketing: theories, practices and devices", Journal of Marketing Management, Vol. 31, No. 1-2, pp. 1-15.

Moriarty, S. and Schultz, D. (2012), "Four theories of how IMC works", in Rodgers, S. and Thorson, E. (Eds.), Advertising Theory, Routledge, New York, pp. 491-505.

Muñoz-Leiva, F., Porcu, L. and Barrio-Garcãa, S.D. (2015), "Discovering prominent themes in Integrated Marketing Communication research from 1991 to 2012: a co-word analytic approach", International Journal of Advertising, Vol. 34, No. 4, pp. 1-24.

Newell, S., Robertson, M., Scarbrough, H. and Swan, J. (2009), Managing Knowledge Work and Innovation, Palgrave Macmillan, Basingstoke, NY.

Nowak, G.J. and Phelps, J. (1994), "Conceptualizing the Integrated Marketing Communications' phenomenon: an examination of its impact on advertising practices and its implications for advertising research", Journal of Current Issues \& Research in Advertising, Vol. 16, No. 1, pp. 49-66.

Nyilasy, G. and Reid, L.N. (2007), "The academician-practitioner gap in advertising”, International Journal of Advertising, Vol. 26, No. 4, pp. 425-445.

Ots, M. and Nyilasy, G. (2015), "Integrated Marketing Communications (IMC): why does it fail?", Journal of Advertising Research, Vol. 55, No. 2, pp. 132-145.

Patti, C.H., Hartley, S.W., Van Dessel, M.M. and Baack, D.W. (in press), "Improving integrated marketing communications practices: a comparison of objectives and results", Journal of Marketing Communications.

Peltier, J., Schibrowsky, J.A., Schultz, D.E. and Zahay, D. (2006), "Interactive IMC: The relational-transactional continuum and the synergistic use of customer data", Journal of Advertising Research, Vol. 46, No. 2, pp. 146-59.

Piekkari, R., Plakoyiannaki, E. and Welch, C. (2010), “'Good' case research in industrial marketing: insights from research practice”, Industrial Marketing Management, Vol. 39 No. 1, pp. 109-17. 
Reckwitz, A. (2002), "Toward a theory of social practices: a development in culturalist theorizing", European Journal of Social Theory, Vol. 5, No. 2, pp. 243-263.

Rose, P.B. (1996), "Practitioner opinions and interests regarding integrated marketing communications in selected Latin American countries", Journal of Marketing Communications, Vol. 2, No. 3, pp. 125-139.

Schatzki, T.R. (2002), The Site of the Social: A Philosophical Account of the Constitution of Social Life and Change, Pennsylvania State University Press, University Park, PA.

Schatzki, T.R. (2005), “The sites of organisations”, Organisation Studies, Vol. 26, No. 3, pp. 465-484.

Schatzki, T.R., Knorr-Cetina, K. and Savigny, E.V. (2001), The Practice Turn in Contemporary Theory, Routledge, New York.

Schau, H., Muñiz, A., Jr. and Arnould, E. (2009), "How brand community practices create value", Journal of Marketing, Vol. 73, No. 5, pp. 30-51.

Schultz, D.E., Kim, I. and Kang, K. (2014). "Integrated Marketing Communication research", in Cheng, H. (Ed.), The Handbook of International Advertising Research, John Wiley \& Sons Inc., Malden, MA, pp. 455-483.

Shove, E. (2007), The Design of Everyday Life, Berg, Oxford, UK.

Skålén, P. and Hackley, C. (2011), "Marketing-as-practice: introduction to the special issue", Scandinavian Journal of Management, Vol. 27, No. 2, pp. 189-195.

Swain, W.N. (2004), "Perceptions of IMC after a decade of development: who's at the wheel, and how can we measure success?", Journal of Advertising Research, Vol. 44, No. 1, pp. 46-65.

Van Maanen, J. (1988), Tales of the Field: On Writing Ethnography, University of Chicago Press, Chicago, IL.

Warde, A. (2005), "Consumption and theories of practice", Journal of Consumer Culture, Vol. 5, No. 2, pp. 131-153.

Whittington, R. (2006), "Completing the practice turn in strategy research", Organisation Studies, Vol. 27, No. 5, pp. 613-634.

Whittington, R. (2007), "Strategy practice and strategy process: family differences and the sociological eye", Organisation Studies, Vol. 28, No. 10, pp. 1575-1586.

Woermann, N. and Rokka, J. (2015), "Timeflow: how consumption practices shape consumers' temporal experiences”, Journal of Consumer Research, Vol. 41, No. 6, pp. 1486-1508.

Yin, R.K. (2006), Case Study Research: Design and Methods, 3rd, Sage, Thousand Oaks, CA.

Zickar, M.J. and Carter, N.T. (2010), "Reconnecting with the spirit of workplace ethnography: A historical review", Organizational Research Methods, Vol. 13 No. 2, pp. 304-19. 